\title{
Gender Perceptions of Female Criminality in China and the United States
}

\author{
Michael Montgomery, PhD a*, Zhu Zeng ${ }^{\mathrm{b}}$ \\ a Department of Criminal Justice, Tennessee State University, 3500 John Merritt Blvd, Nashville, TN 37209. \\ ${ }^{\mathrm{b}} \mathrm{MCJ}$ \\ *Corresponding author's email address: mmontgomery@tnstate.edu.
}

\section{A R T I C L E I N F O}

Received: 04-07-2016

Accepted: 06-08-2016

Available online: $26-08-2016$

Keywords:

Domestic violence;

Female studies;

International crime.

JEL Classification:

D63; F01; I31; J12; K14.

\begin{abstract}
A B S T R A C T
With its rising number and emerging new trends, crime committed by females has become a worldwide concern over the past few decades. A large number of theories have been established to study female criminality with the best knowledge and unique perspectives in different periods. This thesis aimed to compare the different perceptions of the offered causal factors and solutions of female criminality between the people in China and the United States. From October 2015 to January 2016, surveys were distributed in the cities of Ganzhou in China and Nashville, Tennessee in the United States by convenience sampling. Among ten offered causal factors of female criminality, both the Chinese and American participants consider "Vindictive action caused by bad interpersonal relationships" as a critical factor that induces female crime. Beside this, Chinese people consider "Interest-driven, pleasure-seeking and non-performing" as the most important causal factor of female crimes. In contrast, respondents in the United States select "Drugs" as the most critical factor. In regard to the ten listed solutions to female criminality, Chinese people consider that "Better education programs" and "Better legal protection for females" as two leading solutions to reduce female criminality. However, the American respondents do not consider any offered solution as a more effective one over the others. These data indicate that people from China and the United States share some similar perceptions in female criminality, but also hold different views on some of the offered causal factors and solutions. The differences can be likely attributed to the particular situations in each country and people's awareness of female criminality. Thus, further comprehensive studies on the people's concerns will contribute to better understanding of female criminality and better strategies in crime prevention and intervention.
\end{abstract}

This is an open access article under the terms of the Creative Commons Attribution License 4.0, which allows use, distribution and reproduction in any medium, provided the original work is properly cited.

DOI: http://dx.doi.org/10.18533/rss.v1i8.52 ISSN 2378-8569(Print), ISSN 2378-8550(Online)

\subsection{Introduction}

Female criminality is described as the criminal actions that are committed by the female adults (18 years and older) in this paper. Female juvenile delinquency will not be discussed here. No matter which era till today, females have been seen as the foundation of social norms, traditions, customs, and morality. They usually play an indispensable role in maintaining marriage and family stability (Cherian, 2015). It is important to note that female criminality is a social problem that could be a great challenge affecting social harmony.

Throughout a long history of Western civilization, the academic discipline of criminology is marked with gender bias--men dominated, because crime was deemed as an activity mostly associated with males (Heidensohn \& Silvestri, 1996; Smart, 2012). So for a long time, criminology was mainly focused on male offenders or male 
criminality and generally dismissed of female offending (Heidensohn \& Silvestri, 1996; Naffine, 1997). However, with the evolution of society, crime can be hardly considered as an activity only associated with males. Both the absolute number and the relative ratio of female crime have rapidly increased in recent decades (See Table 1, 2 \& 3). Female criminality is no long ignored by criminologists. In contrast, it has drawn considerable attention from the criminologists (Irwin \& Chesney-Lind, 2008; Sharpe, 2012).

Females have many distinctive characteristics different from males which contribute to female criminality. The causes of female criminality include both personal factors and social issues. A variety of factors have been suggested as explanations of female offenders involved in crime, including strong psychological dependence and lack of the ability of self-protection, pleasure-seeking but non-performing, lacking education and legal awareness, marginalization from disrupted personal relationships, sexism and drug crime, economic disadvantage, and the influence of violence culture (Broidy \& Agnew, 1997; Cherian, 2015; Chesney-Lind, 1986; Li, 2010; Richie, 2004). Furthermore, due to differences in social environment, such as culture, political formation, and levels of economic development, people from different countries may have a variety of perceptions regarding the causes and the effectiveness of preventions and solutions of female criminality.

\subsection{Statement of the problem}

Female criminality has become a worldwide concern in recent decades. Not only the number and the ratio of female criminality have increased sharply, but the characteristics or types of female criminality have also changed. Below are the examples of data from China and the United States.

According to the 2012 China Statistical Yearbook, the number of female inmates in prisons increased from 75,870 to 93,051 since 2004 to 2011 (See Table 1). The rate of female inmates in prisons of the total proportion of inmates also increased from $4.85 \%$ to $5.62 \%$ year by year. The overall growth rate of female inmates in prisons was $30.53 \%$ since 2004 to 2011, which is much higher than the overall growth rate of the total proportion of inmates, which is $7.16 \%$ (See Table 2). It is should be noted that the Chinese government did not disclose the specific number of women under custody in the jails, in other words, the relatively systematic national crime statistics are not comprehensive. However, it is still reasonable to conclude that the number of female offenders in jails must also show an increasing trend according to the number of female inmates in prisons. Overall, more women in China are involved in contemporary criminal activity.

\begin{tabular}{lrrr}
\hline \multicolumn{4}{c}{ Table 1: The Number of Female Inmates in China (2004-2011) } \\
\hline Year & $\begin{array}{r}\text { The number of female } \\
\text { inmates }\end{array}$ & $\begin{array}{r}\text { The number of total } \\
\text { inmates }\end{array}$ & $\begin{array}{r}\text { The Percentage of } \\
\text { total (\%) }\end{array}$ \\
\hline 2004 & 75,870 & $1,562,742$ & 4.85 \\
2005 & 77,279 & $1,558,511$ & 4.96 \\
2006 & 77,771 & $1,565,711$ & 4.97 \\
2007 & 78,334 & $1,566,839$ & 5.00 \\
2008 & 80,951 & $1,589,222$ & 5.10 \\
2009 & 85,167 & $1,623,394$ & 5.25 \\
2010 & 90,322 & $1,646,593$ & 5.49 \\
2011 & 93,051 & $1,656,773$ & 5.62 \\
\hline
\end{tabular}

Source: National Bureau of Statistics, China Statistical Yearbook (2012)

\begin{tabular}{|c|c|c|}
\hline Year & $\begin{array}{r}\text { The growth rate of female } \\
\text { inmates (\%) }\end{array}$ & $\begin{array}{r}\text { The growth rate of all } \\
\text { inmates (\%) }\end{array}$ \\
\hline 2004 & 6.43 & 1.07 \\
\hline 2005 & 1.86 & -0.27 \\
\hline 2006 & 0.63 & 0.46 \\
\hline 2007 & 0.72 & 0.07 \\
\hline 2008 & 3.34 & 1.43 \\
\hline 2009 & 5.21 & 2.15 \\
\hline 2010 & 6.05 & 1.43 \\
\hline 2011 & 3.02 & 0.62 \\
\hline The total growth rate of inmates & 30.53 & 7.16 \\
\hline
\end{tabular}

In recent years, both the crime rate and the total prison population decreased in the United States. However, it is disconcerting to see that the criminal activity among women is rising. The report from the Bureau of Justice Statistics of the U.S. also indicates a similar situation as China. It showed that the number of female prisoners 
increased from 98,332 to 112,136 since 2004 to 2009 , with a slight drop in the following two years. The percentage to total increased from $6.8 \%$ to $7.0 \%$ since 2004 to 2011 (See Table 3). From 2000 to 2010, the total number of people under correctional supervision increased. However, the annual growth rate of females under correctional supervision (1.6\% in average) doubled the rate of males $(0.8 \%)$ during the period. Since 2010 , the females in jail have become the fastest expanding group among all correctional population. Annually, it increased by an average of 3.4\% (Glaze \& Kaeble, 2014).

\begin{tabular}{lrrr}
\hline \multicolumn{4}{c}{ Table 1: The number of female prisoners in the U.S (2004-2011) } \\
\hline The number of female & $\begin{array}{r}\text { The number of total } \\
\text { inmates }\end{array}$ & $\begin{array}{r}\text { The Percentage of } \\
\text { total (\%) }\end{array}$ \\
\hline 2004 & 98,332 & $1,497,100$ & 6.8 \\
2005 & 101,972 & $1,525,900$ & 7.0 \\
2006 & 104,797 & $1,568,700$ & 7.0 \\
2007 & 109,257 & $1,596,800$ & 7.1 \\
2008 & 111.544 & $1,608,300$ & 7.1 \\
2009 & 112,136 & $1,615,500$ & 7.1 \\
2010 & 111.071 & $1,613,800$ & 7.0 \\
2011 & 110,478 & $1,599,000$ & 7.0 \\
\hline Sources: Bureau of Justice Statistics $(2012)$ & &
\end{tabular}

In addition to those facts, several new trends have been identified in female criminality, such as crime type, age, and educational levels of offenders. Female crime is not only limited to non-violent crimes, but also includes violent crime. Drug crime, property crime, fraud, human trafficking, arranging for or forcing or sheltering women to engage in prostitution are the most common crime types of female criminality (Li, 2010; United States Sentencing Commission, 2014). About 71 percent of the female offenders had little or no prior criminal history. Women with ages either under 30 or around 40 years form the primary group of female criminality (United States Sentencing Commission, 2014). The number of illiterates is small. Most of the female offenders graduated from junior high school. However, female offenders of position crimes like embezzlement usually have a highlevel education background. Furthermore, females who engage in crime activities are not only referred as the accessory and coerced offenders, but some of them are also the principle criminal in a gang, or commit the crimes by themselves. Except the common characteristics, female offenders in the U.S. have some unique issues. A high percentage of female offenders had backgrounds with mental health and substance abuse issues. In state prisons, nearly 60 percent of female inmates have experienced physical or sexual abuse in the past. What makes it even worse is that most of those assaults occurred when they were young. In addition, 40 percent of female inmates in state prisons are drug abusers (Staton-Tindall, 2010).

\subsection{Purpose of the study}

Female criminality is a global issue currently. Although causes of female criminality are diverse, and each country has its unique formation, it is helpful to study the differences in countries and then discover effective strategies. Any effective measures should bring positive change and can be adopted to reduce the rate of female criminality. The primary goal of this study is to categorize and measure the perceptions of main causes and effective preventions or solutions of female criminality, and to compare the different perceptions between the people in China and the United States. The author also attempts to detect the perceptions of female criminality between different genders.

\subsection{Literature review}

The purpose of this section is to review and analyze the studies related to female criminality and the perception of the ten offered causal factors and solutions of female criminality in China and the United States. This chapter is organized with four sections: a short background introduction to female criminality research, the chronological review of female criminality theories in western countries, the female criminality research in contemporary China including the general characteristics of female crime, and the limitations of current female criminality research, and domestic violence as it is a critical factor which induces female crime in both the two countries.

\subsection{Background introduction}

Gender differences are discussed on a variety of issues in criminology and current studies of criminal justice. However, throughout the development of criminology research, gender bias or gender imbalance is the most obvious feature. Criminologists generally focus on issues related to male offenders (Islam, Bnarjee, \& Khatun, 
2014). They believe that crime is a male-dominated phenomenon and an activity mostly associated with men (Heidensohn \& Silvestri, 1996; Smart, 2012). Fewer females involved in crime than males contribute to the public ignorance of female offending in criminology studies. Female offenders are mentioned only in a few cases, such as compared with male offenders, studies of prostitution, or analyses of the depravity of female violent crime offenders (Curran \& Renzetti, 2001). The paucity of research on female crime has resulted in a shortage of theoretical materials on female criminality and crime (Ahuja, 1996). With the development of the economy and urbanization, the number of female criminals is increasing rapidly. The cases of female criminals are also reported more often than in the past through the mass media. Recently, female criminality has captured much more attention from criminologists. After being ignored for decades, female crime has become much more conspicuous both in academic research and in popular culture (Irwin \& Chesney-Lind, 2008).

\subsection{The history and development of female criminality theories in western countries}

From the early school of positive criminology to the multi-angle and multi-level Modernism School, studies of female criminality have developed for nearly one and a half centuries in the Western countries, with a large amount of theories formed. They explain the causes of female offending, as well as the reasons why women commit fewer crimes than men from a variety of aspects including biological, psychological, economic, and social factors. The quantity and complexity of these theories have expanded greatly in recent years as a part of the growing study on gender in criminology. During this process, some theories were severely criticized or were even rejected gradually due to the lack of scientific rationality. Some other theories, however, have been and are still wildly accepted in the female criminality research field with their broad and deep substantiated basis.

\subsection{From the mid-19th century to the early $20^{\text {th }}$ century}

In the period of mid- $19^{\text {th }}$ to the early $20^{\text {th }}$ century, female criminality research was dominated by the school of positive criminology. As the founder of the Italian school of positive criminology, Cesare Lombroso was one of the earliest criminologists who focused on the female offender and studied female crime from a biological perspective. Since 1895, Lombroso and his disciple Enrico Ferri carried out a series of observations and analyses on the behavior, appearance, personality, and criminality of female inmates. In his well-known anthropological criminology theory, Lombroso concluded that biological throwbacks or deviant inherent features from normal females caused all the criminal behaviors (Klein, 1973). The female offenders are people who are born with criminogenic qualities like a male (Mili, Perumal, \& Cherian, 2015). In addition, as emphasized in his book The Female Offender, those "born criminal" could be identified by their similar physical and psychological defects. For example, he summarized that women who committed homicides often had cranial depressions as well as prominent cheekbones. Women offenders also lacked a maternal instinct but had an excessive desire for revenge, cruelty, greed, etc. (Lombroso, 1898).

Lombroso's perspectives are not supported by scientific evidence, and his study has several limitations. First of all, in the respect to research method, the sampling was limited to female inmates, who could not represent the whole female population. This study did not contain a control group that did not commit a crime. The validity of their study is also affected by the deficiency of an appropriate measurement and scientific evaluation. Secondly, their perspectives overemphasize the single biological factor, and other social, cultural factors are ignored. It is impossible to attribute all female crime entirely to their biological characters. Despite this theory being refuted, Lombroso's biological determinism perspective deeply influenced many theories that came after it (Beaman, 1998; Harry \& Balcer, 1987; Welch, 1997).

Sigmund Freud was another pioneer in this field, with his emphasis on the sexuality and prejudices of women. He assumed that all women experienced the sense of penis envy and vengeance due to the difference between male and female's sex organs. He believed that to compensate for an inferiority complex, women were exhibitionistic and narcissistic (Klein, 1973). Thus, a deviant woman is forcefully rebellious, attempting to be a man. In addition, Freud maintained that women were more interested in irrational and trivial matters instead of social issues (Freud, 1933).

\subsection{From the early $20^{\text {th }}$ century to the mid-20 2 th century}

In this period, although the school of positive criminology was still dominant, the school of criminal sociology began to emerge. W.I. Thomas and Otto Pollak were two leaders in female criminality research of this period. Their theories were mainly based on Lombroso's perspective of biological determinism.

W.I. Thomas's work is mainly focused on psychological factors that explain the causes of female crimes (Van Wormer \& Bartolls, 2000). In his book, The Unadjusted Girl, Thomas demonstrated that female criminal 
behaviors were mainly caused by the women's desires for a new experience, stimulation, and pleasure. For instance, the desire for excitement and response could explain why a woman went into prostitution (Bowker, 1978). Thomas also believed that the desire to break the traditional shackles around the women was another cause of female criminality. Once the women escape from the shackles, they are able to do anything they want. Therefore, he strongly opposed the liberation of women with a thought that it would inevitably lead to a sharp growth in female criminality. Thomas became aware and acknowledged that female criminality reflected the social situation to a certain degree. He suggested that crime such as prostitution correlated with the loss of family and community organization (Thomas, 1967). Although his theory has some early signs of criminal sociology, Thomas's theory was still based on the perspective of biological determinism.

The theory of "hidden" criminality is the most significant part of Otto Pollak's work. He demonstrated that deceitfulness is characteristic of female crimes. This includes two aspects: On one hand, women's physical weaknesses force them to deceive; on the other hand, the biological weakness of females also helps them to deceive the victim (Bowker, 1978). Carrying out his study with a similar viewpoint of Lombroso, Pollak did not agree with every perspective of Lombroso. For instance, Lombroso argued that compared to men, the lower intelligence quotient of women resulted in the lower crime rate of women. However, in Pollak's opinion, women and men have the same intelligence quotient, which leads to a similar level of crime rate for men and women. The reason fewer females committed crimes than males was that not all the cases committed by females were reported and tracked down in time, and some females were given a lesser punishment. Despite the novelty at that time, most of Pollak's propositions were based on assumptions and bias, without the support of evidence (Smart, 2012). In addition, Pollak's research is limited to only petty crimes and not serious crimes. Although Pollak argued that the women's biological nature in a given cultural setting was reflected as their criminality in his book The Criminality of Women, he still believed that female crimes could be explained by women's basic physiological and biological characteristics, among which the psychological factors play a determinant role (Pollak, 1950). However, the discussion of the influence from economy was very limited.

In conclusion, with diverse emphases, all of the theories from the two periods referred to above share some commonalities. First of all, all of them are mainly based on stereotypical assumptions or prejudices of women and sexuality. Secondly, they primarily emphasize biological or psychological traits of females. Distortions from the normal, inherent nature of females was considered as the determinant of female criminal behaviors. The other important factors, however, like the influence of social economics, politics, and social relationships were totally ignored in the traditional theorists' studies. Female offenders are viewed as the results of departures from the normal, inherent nature of women or pathological distortions (Klein, 1973). Clearly, all the traditional theories have the limitation of the times. None of them is able to explain the causes of female crime comprehensively.

\subsection{From the late $20^{\text {th }}$ century to contemporary times}

In the late $20^{\text {th }}$ century, along with the booming of the women's liberation movement, females' voices were being raised for equality, freedom, and liberation. On the contrary, the traditional female criminality research still followed the perspective of "biological determinism" and was based on the gender prejudices. This not only led to a serious deviation in the female criminality research but also totally deviated from the spirit of feminism. Under this background, a group of scholars named "feminist criminologists" emerged and demonstrated that gender should not be ignored or excluded from criminological study. The school of feminist criminology was then established. They asserted that criminology was inherently biased and androcentric due to the patriarchal domination of the field. A variety of new theories have developed since then.

The opportunity theory, also known as the liberation theory, was developed under the social background of the second wave of the women's liberation movement (Mann, 1984). In the late 1960s, under the influence of the feminist movement, the social role of women became a topic of interest and was studied more closely by society. Freda Adler and Rita Simon are two representative scholars of this theory. Adler argued that as the result of striving for equality with men, women obtain not only legitimate opportunities in the labor force but also more opportunities to commit certain types of crimes (Mann, 1984). Proposing a similar argument to Adler's, Simon believed that only certain types of crime are influenced by the women's movement (Simon, 1975). The theory is able to explain the multiple nature of female criminality, but statistics did not support the hypothesis about the relationship between enhanced structural opportunities and the increase in women's offending rates.

Contrary to the opportunity theory, the economic marginalization theory by Clarice Feinman and Ngaire Naffine suggested that the lack of real and meaningful opportunities rather than the increase in new job opportunities for women caused the increased female crime rate. Despite the increase of women in the working force today, there are still many women who are unemployed or working for a minimum wage. Basically, this theory was 
supported by facts and statistics. A huge amount of data demonstrated that the majority of female offenders are unemployed or concentrated in areas where the wage is low and work is unrewarding. This theory is more reliable and valid than the earlier ones. But it is incapable of explaining organization of criminality and why the women who have good economic conditions in the upper class commit crimes.

Feminist criminologists believe that the research of female criminality should be focused on the social problems that reflect serious discrimination between women and men. They explain female criminality from a variety of feminist perspectives such as social status, distribution of social resources, economic disparities, disrupted family and personal relationships, and so on (Bernard, 2013). They made a huge contribution to the female criminality research. With intensive dissatisfaction with the patriarchal society, their research was inevitably under strong influence of personal emotion. Some of their standpoints were criticized due to the inclination of female chauvinism.

Theories of female criminality vary from each other due to the limitation of the era. Each of them provides a distinct angle of view and contributes to the unexplored field of female criminality research. However, every theory regarding causes of female criminality has its limitations no matter which period it came out. Each single crime is committed under certain specific conditions. It is usually a result of the combination of each individual's biological factors and the social factors. Therefore, the cause of crime should be explained from both aspects. The same principle applies to female crime nonexclusively. The influence of the two factors, however, may not be at the same level.

\subsection{Female criminality research in contemporary China}

Studies on female criminality have thrived for more than one hundred years in the Western countries, with a lot of theories formed. However, till the economic boom in the last couple of decades, China lost for more than a century their study of criminology. In the 1920s to 1930s, some of the female criminology theories were first introduced to China from the Western countries for teaching purposes. From then on, female criminality-related writings appeared and increased gradually. From the 1949 Revolution to the 1980s, however, the studies of female criminality were suppressed. With the economic reform started in 1978 and the following unprecedented economic growth and urbanization process thereafter, the number of female crimes also surged rapidly. Since then, female criminality study started to draw attention from the scholars again. Generally speaking, the female criminality research in China is still in an early stage. Among the female research, female criminality research is even marginalized. For example, the first monographic female criminality study was recorded in Women's Studies Yearbook in 1996. Only a few related research studies have been done, and they are limited to prostitution and pornography. The number of research articles on female criminality accounts for a very low percentage among all papers in this field. Therefore, more attention and effort needs to be raised from the public, as well as from the academic fields of sociology, criminology, and feminism research in this country.

\subsection{General characteristics of female crime in contemporary China}

Female crime in China exhibits marked geographical features. Violent crimes are concentrated in northeastern provinces such as Jilin, Heilongjiang, and Liaoning. Property crimes are concentrated in economically developed coastal provinces like Guangdong, Zhejiang, and Jiangsu. The southwestern border provinces are the regions where drug-related crimes happen most (Wu, 2002).

Property crime, sexual offenses, and violent crime are three major types of female crime in China, and female offenders are rarely involved in a wide range of other crimes. Among all the female crimes, property crime accounts for $45 \%$, the sexual offenses accounts for $25 \%$, and the violent crime accounts for $20 \%$ (Zhang \& Zhao, 2001). Of note, the "sexual offense" in this study primarily referred to prostitution or prostitution-related crimes only, and sexual assaults, child sexual abuse, or rape are not included. The increasing prostitution is seen as the adverse consequence of profound economic reforms and the rapid urbanization (Liu, 2012). As a growing social problem, it has raised considerable public concern and cultural disapproval. A major survey indicated that more and more female offenders are involved in violent crimes (Kang, 2005; Wang, 2011). Violent crimes such as murder, robbery, or aggravated assaults were usually attributed to male offenders in the past. However, it is common to find that a variety of violent crimes, even homicide cases, involving female perpetrators are often reported in the mass media now.

Emotional and irrational behavior is also a notable characteristic of female crime in China. On one hand, the vindictive action caused by domestic violence is an important incentive of female crime. Battered women tend to choose violence to fight against their abusers. On the other hand, illegal activities such as trafficking or 
extramarital affairs also cause female crime. Women are inclined to commit sexual offenses or fraud crime when they are unable to properly handle the frustration and adversity during marriage and family life.

In addition, female offenders have some common characteristics in China. Farmers, lower-income workers, and unemployed people comprise the most female offenders. Among them, women who come from rural areas account for a large proportion. Furthermore, most of them have a poor education. Most of the female offenders in China are aged from 18-35 years (Wu, 2002).

\subsection{Limitations of current female criminality research in contemporary China}

The current female criminality research in China has some common limitations. First of all, most of the female criminality research in China is only descriptive studies currently, and quantitative research is very limited. The analyses of the causes of female crime are limited in the aspects of ideological quality, moral standards, or the defect of family and marriage relationships. They lack further research in several areas. For example, why do females commit one specific type of crime more than another type of crime? Secondly, official and periodical national statistics relating to female criminality are not always available. A lot of research is based only on local statistics or patchy national data (Shen \& Winlow, 2014). Thirdly, female offenders are more likely seen as the object rather than the subject. The firsthand resources from the female offender or the voices from them are not given enough attention. Lastly, the causes of female criminality have been attributed to some common reason without enough support from actual data analysis. The psychology of female offenders and other factors are usually ignored in the research.

\subsection{Hypothesis}

The primary hypothesis of this thesis is that people in China and the United States have different perceptions concerning the causes and solutions of female criminality. In addition, two secondary hypotheses are included, and they are:

1. Males and females have different perceptions concerning the causes and solutions of female criminality in both countries.

2. The perceptions of the causes and solutions of female criminality are different in different age groups in both countries.

\subsection{Methodology}

This section is a description of the methodology in the compared study of the perceptions of the causes and solutions of female criminality between the people in China and the United States. This study was reviewed and approved by the Institutional Review Board of Tennessee State University.

\subsection{Participants}

A total of 300 people were planned to recruit for participation in this study, with 150 people from China and 150 people from the United States. The American participants were recruited in Nashville, Tennessee, including students at Tennessee State University and customers found in a local Mall. The Chinese participants were recruited in Ganzhou, China, from the Guoguang Mall and the Golden Square. All the participants are adults 18 years and older.

\subsection{Sampling}

Convenience sampling was used in this study. A convenience sample is one of the main types of non-probability sampling methods. "It is easy to collect initial information, but this method has limited usefulness if the goal is to generalize beyond the sample" (Boslaugh \& Watters, 2008). The informed consent form and survey questions were randomly distributed to any people in the places listed above till the 150 participants were gained in each country. The probability of each selection of population elements was unknown. Each member of the population had an unequal probability of selection because the study chose the target population.

\subsection{Data sources}

Both primary data and secondary data were data sources in this study. The primary data was collected by a descriptive survey design. The secondary data were mainly collected from the sources such as books, journals, and theses related to the study topic. 


\subsection{Instrument}

This study was quantitative research. Primary data were collected by the use of a survey. All the questions in the survey were close-ended questions. This survey consisted of three multiple choice questions about the participants' personal demographics, two forced Likert scale questions, and two ranking questions to collect the opinions about the causal factors and solutions to female criminality. An informed consent form had to be signed before the participant answered the questions. The participants could stop completing the survey at any time they wanted. The survey was anonymous. The informed consent forms and completed surveys were kept separately.

\subsection{Data processing and analysis}

Both descriptive and inferential statistical tools were used to analyze the data. After collected from the surveys, the data were entered into Microsoft Excel, and basic descriptive statistics were calculated in the worksheets. GraphPad Prism 6 was used for further data analysis. For the offered causal factors and solutions of female criminality, the ranking scores given by Chinese and American participants were analyzed with two-way analysis of variance (ANOVA) followed with multiple comparisons (Cronk, 2006). Two-way ANOVA was also used to determine the influence of gender or age on the ranking scores given from the two countries to each offered causal factor or solution. With scores given to the ten causal factors and solutions of female criminality, Spearman correlation coefficient (Cronk, 2006) was calculated to assess the distributions of the perspectives from Chinese and American participants on each offered causal factor or solution.

\subsection{Results and findings}

\subsection{Overview}

A total of 254 people in different gender and age groups from China and the United States were recruited in this study. In each country, 150 surveys were distributed in locations mentioned in Chapter Three. The data of 150 Chinese respondents and 104 American respondents were collected. The reply rates were $100 \%$ in China and $69.3 \%$ in the United States. Due to incompletion or misunderstanding of the survey instructions, 45 invalid responses were excluded, and valid data were then analyzed. The demographic distribution of samples is shown in Table 4 below.

\begin{tabular}{lrrr}
\hline & Table 2: Frequency distribution of sample & \\
\multicolumn{1}{c}{ Attributes } & China & U.S. & Total \\
& N=127 & N=82 & N=209 \\
\hline Gender & & & \\
Male - No. (\%) & $55(43.3)$ & $31(37.8)$ & $86(41.1)$ \\
Female - No. (\%) & $72(56.7)$ & $51(62.2)$ & $123(58.9)$ \\
\hline
\end{tabular}

4.2 Overall perceptions of ten offered causal factors of female criminality in China and the United States

To evaluate the people's attitude about the possible causes of female criminality in China and the United States, the respondents were asked to give ranking score to each offered causal factor from 1 to 10 , with 1 for the minimal influence and 10 for the maximal influence. The overall ranking scores of the offered causal factors of female criminality are illustrated in Table 5, with data normalized to gender and age. In this study, if the respondents gave each factor a score randomly, or if they held an indifferent attitude toward a factor, the chance of a factor being ranked with one of the scores from 1 to 10 would equally be $10 \%$, and the average score of each factor from all respondents would converge toward 5.5. The scores were analyzed with two-way ANOVA followed by multiple comparisons. In this study, any factor with a final score significantly higher than 5.5 suggests a priority in people's minds. Conversely, a score lower than 5.5 means less importance. The Spearman correlation coefficient was used to determine the strength of the relationship of perspectives of the offered causal factors and solutions of female criminality between the Chinese and American respondents.

Chinese people considered "Interest-driven, pleasure-seeking and non-performing" as the most critical causing factor of female crime. However, American people considered "Drugs" as the most important factor of female crime. No significant correlation was achieved with Spearman correlation coefficient analysis in these two factors between the Chinese people and the American people. In addition, Chinese people consider "Gender discrimination" as the least important causal factor of female crime. However, this tendency was not seen in the American people. 
Interestingly, both Chinese and American respondents considered "Vindictive action caused by bad interpersonal relationships" as an important factor that caused female crime, with a positive correlation of opinions from these two countries. The other listed factors did not gain scores that were statistically different to 5.5 or each other except those factors mentioned above.

Following ranking the ten listed causal factors, the respondents were also asked for their overall acceptance of these factors with a forced Likert scale question. Among all participants, $66 \%$ respondents from China and $83 \%$ respondents from the U.S. strongly or partly agreed that these ten offered factors influence female criminality.

Table 3: Overall weighted scores and the actual rankings of the offered causal factors

Causal Factors

China

Mean+SEM

Strong psychological dependence and lack of the ability of selfprotection

Interest driven, pleasure-seeking and non-performing

Lack of education and the knowledge of the law

Vindictive action caused by bad interpersonal relationships

Influence of the violence culture

Drugs

Sex and pornography businesses

Gender discrimination

Using the Internet or telephone services for illegal purposes

More work opportunities providing for crimes related to specific positions

Note. The bolded numbers indicate that the value is statistically different from the average score of 5.5 with $\mathrm{p}<0.05$. The numbers in parentheses indicate the actual ranks of the ten offered causal factors of female criminality.

Table 4: The correlation of the perceptions on the offered casual factors of female criminality between China and the United States

Causal Factors

Strong psychological dependence and lack of the ability of self-protection

Interest driven, pleasure-seeking and non-performing

Lack of education and the knowledge of the law

$4.86 \pm 0.29(4)$

$5.18 \pm 0.31(5)$

$7.56 \pm 0.23(10)$

$5.83 \pm 0.27(8)$

$7.00 \pm 0.22(9)$

$5.32 \pm 0.22(5)$

$5.79 \pm 0.23(7)$

$5.76 \pm 0.22(6)$

$3.32 \pm 0.23(1)$

$4.80 \pm 0.19(3)$

$5.62 \pm 0.30(7)$

$6.91 \pm 0.28(9)$

$6.19 \pm 0.26(8)$

$7.28 \pm 0.28(10)$

$5.33 \pm 0.31(6)$

$4.53 \pm 0.34(2)$

$4.78 \pm 0.30(3)$

$4.32 \pm 0.29(1)$

Vindictive action caused by bad interpersonal relationship

Influence of the violence culture

Drugs

Sex and pornography businesses

Gender discrimination

Using the Internet or telephone services for illegal purposes

More work opportunities providing for crimes related to specific positions

Note. P values less than 0.05 are in bold.

\subsection{Overall perceptions of offered solutions of female criminality in China and the United States}

With the same statistical methods on the causal factors described above, the ranking scores of the offered solutions were also analyzed.

As shown in Table 7, Chinese respondents exhibited preference for some of the proposed solutions to the others. Chinese respondents considered "Better education programs for females" and "Better legal protection for females" as two most effective solutions to reduce the female criminality. However, the American respondents had indifferent attitudes to these two, and there were no correlation between the Chinese and American perspectives. "Better programs for alcohol and drug abuse" was the only solution with a significant negative correlation between the Chinese and American perspectives. For the other proposed solutions, no significant preference or correlation was detected from respondents.

Following ranking the ten possible solutions, overall acceptance of these solutions was also assessed with a forced Likert scale question. Among all participants, $69 \%$ Chinese and $78 \%$ U.S. respondents strongly or partly agreed that these ten proposed solutions are effective. 
Table 5: Overall weighted scores and the actual rankings of the offered solutions

\begin{tabular}{lrr} 
Solutions & $\begin{array}{r}\text { China } \\
\text { Mean } \pm \text { SEM }\end{array}$ & $\begin{array}{r}\text { U.S. } \\
\text { Mean } \pm \text { SEM }\end{array}$ \\
\hline Intensify the fight against drug crimes & $6.24 \pm 0.24(7)$ & $5.35 \pm 0.32(5)$ \\
Strengthen the enforcement of the sex businesses & $6.59 \pm 0.21(8)$ & $5.35 \pm 0.32(4)$ \\
Manage the unemployment rate in certain communities & $5.33 \pm 0.23(6)$ & $5.07 \pm 0.29(2)$ \\
Special care for women offenders in community corrections & $5.27 \pm 0.21(5)$ & $5.40 \pm 0.30(6)$ \\
Better education programs for females & $6.84 \pm 0.25(9)$ & $5.77 \pm 0.30(7)$ \\
Better legal protection for females & $7.45 \pm 0.22(10)$ & $5.77 \pm 0.32(8)$ \\
Better rehabilitation programs in jails and prisons & $4.26 \pm 0.20(2)$ & $6.16 \pm 0.30(10)$ \\
Provide more daycare so females can enter the workforce & $4.93 \pm 0.24(4)$ & $4.99 \pm 0.32(1)$ \\
Better programs for alcohol and drug abuse & $4.27 \pm 0.23(3)$ & $5.98 \pm 0.31(9)$ \\
Eliminate discrimination against women & $3.83 \pm 0.28(1)$ & $5.21 \pm 0.37(3)$ \\
Note. The bolded numbers indicate that the value is statistically different from the average score of 5.5 with p<0.05. The & \\
numbers in parentheses indicate the actual ranks of the ten offered solutions of female criminality.
\end{tabular}

Table 6: The correlation of the perceptions on the ten solutions of female criminality between China and the United States

$\begin{array}{lrr}\text { Solutions } & \text { Spearman r } & \text { P value } \\ \text { Intensify the fight against drug crimes } & -0.056 & 0.800 \\ \text { Strengthen the enforcement of the sex businesses } & 0.069 & 0.850 \\ \text { Manage the unemployment rate in certain communities } & 0.463 & 0.178 \\ \text { Special care for women offenders in community corrections } & 0.489 & 0.154 \\ \text { Better education programs for females } & -0.220 & 0.512 \\ \text { Better legal protection for females } & 0.255 & 0.472 \\ \text { Better rehabilitation programs in jails and prisons } & -0.506 & 0.132 \\ \text { Provide more daycare so females can enter the workforce } & 0.364 & 0.298 \\ \text { Better programs for alcohol and drug abuse } & -0.746 & 0.014 \\ \text { Eliminate discrimination against women } & 0.634 & 0.053\end{array}$

Note. $\mathrm{P}$ values less than 0.05 are in bold.

\subsection{Perceptions of causal factors of female criminality from males and females}

To determine if males and females have different perceptions concerning the ten listed causal factors of female criminality, the data from Chinese and American respondents were further categorized according to their genders (male and female), and the scores of each causal factor were analyzed by two-way ANOVA. The mean scores and standard errors of each subgroup were included in Figure 3. No statistical significant gender difference was found in all ten factors. However, significant differences were still detected between two countries in the second and sixth causal factors as mentioned above, and there was no interaction between the country and gender variables.

\subsection{Perceptions of solutions of female criminality from males and Females}

Similarly, to determine if males and females have different perceptions concerning the solutions of female criminality, the data from two countries were further categorized according to respondents' genders (male and female), and the scores of each causal factor were analyzed by two-way ANOVA. The mean score and standard error of each subgroup were plotted in Figure 4. No statistical significant gender difference was found in all the offered causal factors. Significant differences between the two countries were still detected as mentioned above. No interaction was detected between the country and gender variables.

\subsection{Conclusions and discussion}

\subsection{Conclusions}

This study provides evidence that people from China and the United States share some common perceptions of female criminality, but they also have distinctive perceptions that are different from each other. These differences are not only reflected in the offered causal factors but also reflected in solutions. Both the Chinese and American participants consider "Vindictive action caused by bad interpersonal relationships" as a critical factor that motivates female crime. Interestingly, Chinese people consider "Interest driven, pleasure-seeking and non-performing" as the most important causal factor of female crimes; however, respondents in the United States select "Drugs" as the most critical factor. In regard to the ten listed solutions to female criminality, 
Chinese people consider that "Better education programs" and "Better legal protection for females" are the two top leading solutions to reduce female criminality. The American respondents do not have a consensus of an effective or non-effective solution according to the data collected from the current survey. However, there are two offered solutions showed a trend of higher importance and reflected some preferences of the American participants. They are "Better rehabilitation programs" and "Better programs for alcohol and drug abuse", but a larger sample size is required to confirm these speculations.

The study indicates that gender does not play a difference in perceptions of female criminality.

\subsection{Discussion}

The Chinese respondents consider "Interest driven, pleasure-seeking and non-performing" as the most important causal factor among those offered factors, which reflects the influence of Chinese traditional culture. For thousands of years, people's ideas have been profoundly influenced by Confucian philosophy in almost every aspect in China. In this ideology, a good woman should be kind, diligent, capable of taking good care of her family, and have a high moral standard. Since the late twentieth century, a good woman is also expected to enter the workforce and support the household financially. Although the public is much more tolerant of some of women's behavior, such as pre-marital sexual relationships, divorce, and even extra-marital affairs than ever before, the strict traditional moral codes still deeply influence Chinese people's thoughts. Therefore, most female offenders, especially those who commit economical or sexual crimes, are often considered as bad women. They are usually described as "greedy," "lazy," "'twisted," "morally rotten," or "lacking of dignity" (Shen \& Winlow, 2014). This perspective of the Chinese respondents is similar to the traditional biological determinists' theories of female criminality, especially W.I. Thomas's arguments. Thomas argued that female criminal behaviors were mainly caused by the women's desires for a new experience, stimulation, and pleasure. Chinese respondents believe that female offenders are usually lazy, easy to be tempted, and controlled by their material desire. According to the results from this study, Chinese people believe that the personality is the key factor in motivating female crimes, and they are not so aware of factors such as social development, economical changes, and cultural factors. This Chinese perspective is both conservative and stereotypical. It may also suggest that the amount of research and the public awareness of female criminality are still limited in contemporary China. The problem of female criminality does not receive enough attention from the scholars. Comprehensive research and deep exploration are lacking in the female criminality field.

In contrast, the United States is a population of immigrants. Their descendants include cultures inherited from many different ethnical and racial groups throughout the world, and the people in the United States have much more diverse opinions of female criminality. Also, people in the United States have better educational opportunities than people in China (United Nations Development Program, 2013). Therefore, it is very likely that American people take social, economic, and cultural factors into consideration, and "Interest driven, pleasure-seeking and non-performing" is not chosen as the most important motive causal factor by them.

Among the ten offered causal factors of female criminality, the most important factor chosen by the American respondents was "Drugs," which does not cause much concern from the Chinese participants. The drug problem has a long history in the United States, and has been described as "crossing all gender, racial, economic, and social lines" in this country (Reagan, 2013). President Nixon declared war on drugs in 1971. In order to fight against illegal drug use and drug activities, both the federal and local governments have spent a large amount of money since then. In every category, such as race, age and income, fewer women than men use drugs. However, a notable number of women do engage in drug use. According to a study conducted by the National Institute on Drug Abuse, $34.8 \%$ of white women surveyed have used drugs, and $29.6 \%$ black and $26.9 \%$ Latina women have also used illicit drugs in the same time period (Reagan, 2013).

In fact, plenty of studies have provided convincing evidence for a strong link between drug abuse and females offending in the United States. Although the crime rate for women is much lower than the crime rate for men, the criminality of women is more closely related to their drug use than it is for men (Pollock, 1999). In the past few decades, arrests of females for drug offenses have more than tripled compared with male arrests. Many female offenders attribute their own offending to drug and alcohol abuse (Indermaur, 1995). About 60\% of women in U.S. prisons used drugs in the month prior to their current offense, and one in four of them were under the influence of drugs at the time of their offense (Ekstrand, 1999). About $65 \%$ of inmates in local jails in the US were actively drug-involved at the time of the offense (Wilson, 2000). Furthermore, drug abusers tend to be involved in other illegal activities when they are lacking money for drugs. For example, addicted women may exchange sex for illegal drugs when they have no money. 
In the Chinese respondents' opinion, a drug problem is not in the priority list of the female criminality. This can be explained in several possible aspects. First of all, the drug problem did not become apparent until the economic development of China. After World War II and the Chinese Civil War, China was under strict political control with limited economic development in the twentieth century. People were struggling for the basic living standards due to the scarcity of goods at that time. Until 1979, the Economy Reform and Opening started to be implemented in China. Since then, the economy and people's living standards have been improving yearly, as well as an increase in drug-related crimes. Secondly, all the respondents in China were recruited from Ganzhou, a small city located in southeastern inland China. The crime rate of drug activities is much lower in Ganzhou. China is a large country with huge regional differences in geography, economy, and culture. The most severe drug crimes usually occur in the costal economic development area, or the provinces in southwestern China like Yunnan province, Guangxi province located nearby the Golden Triangle-- one of Asia's two main opiumproducing areas.

From 2006 to 2011, drug crimes more than doubled, and drug-related cases are the fourth most common type of criminal case in China (Tong \& Yan, 2012). Surprisingly, 87\% of crimes committed by Chinese women are nonviolent, and $42 \%$ of them are drug-related (Hatton, 2015). Therefore, drug abuse as a causal factor of female criminality is not negligible but underestimated by Chinese respondents. Without direct data from Ganzhou, a report from a nearby city Jiujiang indicates a marked increase in crimes committed by females from 2010 to 2012. As a major category, drug-related crimes have more than doubled (Zhejiang Narcotics Control Association, 2013). It is possible that "Drugs" is becoming an induced causal factor in China and the city of Ganzhou is also facing the same challenge, but the people are not aware.

\subsection{Perceptions of solutions}

The Chinese participants consider providing better legal protection and better education to women as the most effective ways to solve the problem of female criminality because in their opinions, the personal factors of the female offender are the key motivating causal factor. Most female offenders in China lack legal awareness and education.

Indeed, those perspectives are consistent with the Chinese government's attitude. In order to provide better legal protection and better education for women, a series of laws, regulations, and policies were approved and implemented recently in China. For example, the "People's Republic of China Anti-Domestic Violence Law" was approved by the Standing Committee of the National People's Congress on December 27, 2015 and will be implemented from March 1, 2016. This law enables a zero tolerance principle, and will provide full protection to the victims of domestic violence.

In the past, purchasing trafficked women or children was not regarded as a criminal act and would not result in criminal sanctions in accordance with the Criminal Law of China, as long as the buyer did not abuse the trafficked women or children and did not hinder the rescue activities. However, this provision was changed in the Ninth Amendment of the Criminal Law of China, which was approved by the Standing Committee of the National People's Congress on August 29, 2015 and implemented from November 1, 2015. Consequently, the $15^{\text {th }}$ article of the Amendment states "all the people who purchase the trafficked women or children will be sentenced even if they do not misuse them or hinder their rescue" (The Ninth Amendment of the Criminal Law of China Feminist Majority Foundation, 2015).

Also, in the aspect of policy, the Chinese government published the Development Guidelines of Chinese Women (2011-2020). It points out that the Chinese government will guarantee the right of education equally, and aim at eliminating the phenomenon of girls dropping out of school to improve the education conditions and increase the education resources in rural areas (P.R.C. State Council, 2011).

These measures indicate that the Chinese government pays attention to the solutions of female criminality gradually. The measures and the government's interest are good for improving the process of solving the problem of female criminality.

In contrast, the American respondents did not have a consistent opinion in the ten offered solutions. It is unlikely that the most effective solution for female criminality, believed by Americans is not included in the offered ten, because the result shows that about $78 \%$ of U.S. respondents strongly or partly agreed that these ten proposed solutions are effective. However, $22 \%$ of American respondents did not agree or were undecided about the effect of those ten offered solutions. It is interesting that no single solution has received a higher statistical significant score than the others. One explanation is that the American participants considered each solution equally important. No single solution is more effective than the other to solve the problem of female 
criminality. Each solution plays a role in specific field to solve certain motivating factors. Combining the solutions together will be the best way to prevent or solve this problem.

\subsection{Limitations}

This study has several limitations. First, a random sampling was not used in this study. So the results of the study cannot be generalized to both the American and Chinese populations. All the respondents were selected in the specific areas by purpose. The respondents in America were mainly college students, and other professions were less questioned. It inevitably affects the validity of this study. Secondly, the sampling size is not large enough to represent the comprehensive situation and large populations of those two countries. The sample size might be too narrow to detect differences that actually exist. Thirdly, with the limitation of education level or other factors, some respondents misunderstood the survey instruction of rank-order questions. This affects the results to a certain degree. Finally, as a quantitative questionnaire study, it has certain inevitable limitations. All the questions are close-ended questions in the survey. Especially, the offered causal factors and solutions were provided based on the researcher's limitation of knowledge. Therefore, some other causal factors or solutions which the respondent considered important might be missed.

\subsection{Recommendations for future research}

Without a doubt, random sampling is a better choice for future study. To compare two large countries, it is better to obtain samples from diverse areas with different cultural environments, economical level, and demographic features. When it comes to further research on this topic, researchers can use some other variables such as education level, annual income, and marital status in addition to the gender, nationality and age. Some open-ended questions can be added in the survey in order to get more comprehensive information from the respondents in the future research.

\section{References}

Ahuja, R. (1996). Sociological Criminology. New Delhi: New Age International Publishers Limited.

Beaman, L. G. (1998). Women's Defences: Contextualizing dilemmas of difference and power. Women \& Criminal Justice, 9(3), 87-115. http://dx.doi.org/10.1300/J012v09n03_04

Bernard, A. (2013). The Intersectional Alternative: Explaining female criminality. Feminist Criminology, 8(1), 3. http://dx.doi.org/10.1177/1557085112445304

Boslaugh, S., \& Watters, P. A. (2008). Statistics in Nutshell. Sebastopol, California: O'Reilly Media, Inc.

Bowker, L. H. (1978). Women, Crime, and the Criminal Justice System. Lexington, MA: Lexington Books.

Broidy, L., \& Agnew, R. (1997). Gender and Crime: A General Strain Theory Perspective. Journal of Research in Crime and Delinquency, 34(3), 275-306. http://dx.doi.org/10.1177/0022427897034003001

Cherian, N. S. (2015). Female Criminality in India: Prevalence, Causes and Preventive Measures. International Journal of Criminal Justice Sciences, 10(1), 65-76.

Chesney-Lind, M. (1986). Women and Crime: The Female Offender. Chicago: University of Chicago Press.

Cronk, B. C. (2006). How to Use SPSS. Glendale, California: Pyrczak Publishing.

Curran, D. J., \& Renzetti, C. (2001). Theories of Crime. Boston: Allyn and Bacon.

Ekstrand, L. (1999). Women in Prison: Issues and Challenges Confronting US Correctional Systems. Washington DC: United States General Accounting Office.

Feminist Majority Foundation. (2014). Domestic Violence Resources. Retrieved from http://www.feminist.org /other/dv/dvfact.html

Freud, S. (1933). New Introductory Lectures on Psycho-Analysis. New York: Norton.

Glaze, L. E., \& Kaeble, D. (2014). Correctional Populations in the United States, 2013. Washington, DC: US Department of Justice, Office of Justice Programs, Bureau of Justice Statistics.

Harry, B., \& Balcer, C. M. (1987). Menstruation and Crime: A critical review of the literature from the clinical criminology perspective. Behavioral Sciences \& the Law, 5(3), 307-321. http://dx.doi.org/10.1002/bsl.237 0050306

Hatton, C. (2015, June 25). Why is China's Female Prison Population Growing? Retrieved from http://www.bbc.com/news/blogs-china-blog-33268611

Heidensohn, F., \& Silvestri, M. (1996). Women and Crime. New York: Macmillan. http://dx.doi.org/10.1007/978$1-349-24445-4$

Indermaur, D. (1995). Violent Property Crime. Sydney: Federation Press.

Irwin, K., \& Chesney-Lind, M. (2008). Girls' Violence: Beyond dangerous masculinity. Sociology Compass, 2(3), 837-855. http://dx.doi.org/10.1111/j.1751-9020.2008.00120.x 
Islam, M. J., Bnarjee, S., \& Khatun, N. (2014). Theories of Female Criminality: A criminological analysis. International Journal of Criminology and Sociological Theory, 7(1), 1.

Kang, S. H. (2005). A Study on Current State and Characteristics of Chinese and Foreign Female offending. Academic Forum of Nandu (Journal of the Humanity and Social Sciences), 25(3), 85-92.

Klein, D. (1973). The Etiology of Female Crime: A review of the literature. Criminology, 8(2), 3-30.

Li, M. (2010). Discussion on the Causes of Female Crime and Its Control and Prevention. M \& D Forum, 197.

Liu, M. (2012). Chinese Migrant Women in the Sex Industry: Exploring Their Paths to Prostitution. Feminist Criminology, 7(4), 327-349. http://dx.doi.org/10.1177/1557085112436836

Lombroso, C. (1898). The Female Offender. New York: Appleton.

Mann, C. R. (1984). Female Crime and Delinquency. Tuscaloosa: University of Alabama Press.

Mili, P. M. K., Perumal, R., \& Cherian, N. S. (2015). Female Criminality in India: Prevalence, Causes and Preventive Measures. International Journal of Criminal Justice Sciences, 10(1), 72.

Naffine, N. (1997). Feminism and Criminology. Cambridge: Polity Press.

P.R.C. State Council. (2011). China National Program for Women's Development (2011-2020).

Pollak, O. (1950). The Criminality of Women. Philadephia, PA: University of Pennsylvania Press.

Pollock, J. M. (1999). Criminal Women: Anderson Pub Co.

Reagan, B. (2013). The War on Drugs: A War against Women. Berkeley Journal of Gender, Law \& Justice, 6(2), 204.

Richie, B. E. (2004). Feminist ethnographies of women in prison. Feminist Study, 30(2), 438-450. http://dx.doi.org/10.2307/20458973

Sharpe, G. (2012). Offending Girls: Young Women and Young Justice. London: Routledge.

Shen, A., \& Winlow, S. (2014). Women and Crime in Contemporary China: A review essay. International Journal of Comparative and Applied Criminal Justice, 38(3), 333. http://dx.doi.org/10.1080/01924036.2013.8613 54

Simon, R. J. (1975). Women and Crime. Lexington, MA: Lexington Books.

Smart, C. (2012). Women, Crime, and Criminology: A Feminist Critique. London: Routledge.

Staton-Tindall, M. (2010). Female offender drug use and related issues. Retrieved from http://www.nij.gov/ topics/drugs/markets/adam/documents/staton-paper.pdf

The Ninth Amendement of the Criminal Law of China, (2015).

Thomas, W. I. (1967). The Unadjusted Girl. New York: Harper \& Row.

Tong, J., \& Yan, P. (2012, 2015 June 27). The Analysis of Drug Cases in China from 2007 to 2011. China Court. Retrieved from http://www.chinacourt.org/article/detail/2012/06/id/530295.shtml

United Nations Development Program. (2013). Human Development Reports - Education index. Retrieved from http://hdr.undp.org/en/content/education-index

United States Sentencing Commission. (2014). Quick Facts on Female Federal Offenders. Retrieved from http://www.ussc.gov/sites/default/files/pdf/research-and-publications/quick-facts/Quick_Facts_ Female_Offenders.pdf

Van Wormer, K. S., \& Bartolls, C. (2000). Women and the criminal justice system. Boston: Allyn and Bacon.

Wang, M. (2011). New Criminology (2nd ed.). Beijing: Higher Education Press.

Welch, M. (1997). Regulating the Reproduction and Morality of Women. The Social Control of Body and Soul, 9(1), 17-38. http://dx.doi.org/10.1300/j012v09n01_02

Wilson, D. (2000). Drug Use, Testing and Treatment in Jails. Washington DC: Bureau of Justice Statistics, US Department of Justice. http://dx.doi.org/10.1037/e482262006-001

$\mathrm{Wu}, \mathrm{M}$. (2002). The Female Criminality Research from the Perspective of Sociology in Comtemporary China. Fuzhou: Fuzhou University Press.

Zhang, X., \& Zhao, G. (2001). The Crime Control in Contermporary China. Beijing: Peking University Press.

Zhejiang Narcotics Control Association. (2013). Jiujiang: Drug-related Female Crimes are increasing. Retrieved from http://www.zjjd.org/jdfz/content/2013-03/08/content_10983.htm 